the other hand, I had simply called them vertebro-basilar ischaemia, my figures for no diagnosis would clearly have fallen, but enlightenment would hardly have followed.

G D PERKIN Charing Cross Hospital, London, United Kingdom

1 Perkin GD. Basic Neurology. Chichester: Horwood, 1986.

Do leukocytes have a role in the cerebral no-reflow phenomenon?

Aspey et $a l^{1}$ failed to demonstrate any difference in either the incidence or severity of the no reflow phenomenon induced by severe cerebral ischaemia in gerbils rendered leukopenic by pretreatment with cyclophosphamide as compared to controls. The authors have suggested that the absolute number of leukocytes is of limited value in the no reflow phenomenon. We would like to make the following points: first, it may be invalid to compare data derived from humans suffering from focal ischaemia, and probably having coexistent atherosclerotic disease, to that obtained from an experimental model of total bilateral hemispheric ischaemia in gerbils with an intact cerebral circulation. Secondly the results do not take into consideration the qualitative role of leukocytes in ischaemia, that is, ischaemic related no reflow phenomenon induced by activation of blood cells and the role of the individual leukocyte subpopulations during ischaemia. Furthermore, comments on the subtype of blood cell responsible for plugging of capillaries are not valid given the method used.

Our own interest in leukocytes and cerebral ischaemia led us to study the rheological behaviour of blood cell subpopulations, that is, red blood cell, granulocyte and mononuclear leukocytes, in 20 males suffering from acute cerebral infarction compared to 20 agematched healthy controls. The filterability of blood cells, separated using Ficoll-Hypaque density gradient after centrifugation, were determined following the technique of Lennie et al. $^{23}$ This method enables investigation of blood cell subpopulations under similar conditions and above all, results are unaffected by the number of cells, platelet contamination, or plasma protein interactions. Filterability is expressed as a pressure ratio of cell suspension to buffer after six minutes filtration. Our results suggested that mononuclear leukocyte and granulocyte filterability was impaired in cerebral infarction $[7.26$ (SD) 2 and 5.75 (SD) 0.87 respectively] compared to controls [5.55 (SD) 1.23 and $4 \cdot 19$ (SD) 0.45 ], while no differences existed in red blood cells. Furthermore we have obtained similar results in a human model of treadmill-induced, controlled ischaemia in stage II peripheral artery disease $^{3}$ and coronary artery disease (unpublished material). These studies provide evidence that leukocytes are functionally altered under ischaemic conditions.

The mechanism leading to the altered filterability of leukocytes during ischaemia is not fully understood. It has, however, been suggested that leukocyte activation may occur as a consequence of ischaemia ${ }^{4}$ and may contribute to the ischaemia by releasing vasoactive substances and mechanically obstructing capillaries. ${ }^{5}$ Furthermore, activation of the cells impairs their filterability. ${ }^{6}$
This hypothesis concurs with our results since the filtration procedure measures the ability of cells to pass through the pore-filter, whose diameter of 5 microns approximates the diameter of capillaries. We feel an important issue is the role of leukocyte activation in the pathogenesis of the no reflow phenomenon. While Aspey et al have studied the role of the absolute leukocyte count, they have not considered leukocyte behaviour. I would be interesting to assess the filterability or the percentage of activated cells in the neutropenic compared to the control group It may be that only a small number of activated leukocytes are required to contribute to the no reflow phenomenon.

MICHELE MERCUR

GIOVANNI CIUFFETT RITA LOMBARDIN CHRISTIANA NER

Laboratorio di Emoreologia Clinica, Istituto di Clinica Medica II, Universita' di Perugia, Perugia, Italy MARTIN ROBINSON Stroke Research Center,
Stron Bowman Gray School of Medicine, ake Forest University, Winston Salem, NC
United State

1 Aspey BS, Jessimer C, Pereira S, Harrison MJG. Do leukocytes have a role in th cerebral no-reflow phenomenon? J Neurol Neurosurg Psychiatry 1989;52:526-8.

2 Lennie SE, Lowe GDO, Barbenel JC, Forbes CD, Foulds WS. Filterability of white blood cell subpopulations separated by an improved method. Cl Hemorheol 1987;7:811-6.

3 Ciuffetti G, Mercuri M, Mannarino E Robinson MK, Lennie SE, Lowe GDO. PeriRobinson MK, Lennie SE, Lowe GDO. Peripheral vascular disease. Rheologic variables during controlled

4 Violi F, Rasura M, Alessandri C, Intiso D Germani M, Servi M, Fieschi C, Balsano F. Leukocyte response in patients suffering from acute stroke. Stroke 1988;20:165-70.

5 Weiss SJ. Tissue destruction by neutrophils. $N$ Engl J Med 1989;320:365-76.

6 Nash GB, Thomas PRS, Dormandy JA. Abnormal flow properties of white blood cells in patients with severe ischaemia of the leg. $B$ Med J 1988;296:1699-701.

\section{Dr Aspey et al reply:}

We were interested to see the in vitro results of reduced leukocyte filterability following stroke reported by Mercuri et al. We accept that our results ${ }^{1}$ do not address the issue of leukocyte activation during cerebral ischaemia. What remains to be shown is that a behavioural change in any subpopulation of leukocytes is of pathological significance in the brain. Only interventional studies are likely to achieve this as has been attempted in the case of experimental myocardial ischaemia where reducing total leukocyte number improves post-ischaemic perfusion. ${ }^{2}$ Our failure to show a parallel change in the brain raises the possibility that the microcirculations of brain and heart differ in their responses to ischaemia.

\section{BENJAMIN ASPEY CATHERINE JESSIMER STELLA PEREIRA \\ MICHAEL HARRISON \\ The Reta Lila Weston Institure Studies, University College and Middlesex School of Medicine, London}

1 Aspey BS, Jessimer C, Pereira S, Harrison MJG. Do leukocytes have a role in the cerebral no-reflow phenomenon? J Neurol Neurosurg Psychiat 1989;52:526-8.

Romson JL, Hook BG, Rinkel SL, Abrams ED Short MA, Lucchesi BR. Reduction of the extent of ischemic myocardial injury by neutrophil depletion in the dog. Circulation 1983;67:1016-23.

\section{BOOK REVIEWS}

Medical Malpractice Solutions: Systems and Proposals for Injury Compensation Edited by MM HALLEY, RJ FOWKS, FC BIGLER AND DL RYAN. ( $P p$ 305; \$49.75). Illinois: Charles C Thomas, 1989.

The escalating number of medical negligence claims and the delays, costs and uncertaintie of the present legal process have led the four editors, two surgeons and two lawyers, al from Kansas, to put forward their proposals to replace the existing legal procedures by a Model Medical Accident Compensation Act. They are assisted by eleven other contributors, four doctors, five lawyers and two in the field of finance and insurance. The solution to the problem is proposed in the setting of United States law but Richard Smith (Senior Assistant Editor of the British Medical Journal), describes the present situation in Great Britain, Diana Brahams (legal correspondent of The Lancet), describes the Swedish and Finnish patient insurance schemes, and Sir Owen Woodhouse (Chairman of the Royal Commission on Compensation and Rehabilitation for Personal Injury in New Zealand), describes the experiences in that country.

The first four chapters deal with the history and development of the law of tort and the effect that this has had upon medical care in the United States and in this country. The second part of the book deals with othe proposals which involve a greater or lesser degree of reform of the existing legal system or its replacement by arbitration. Part three deals with the systems of arbitration which exist in New Zealand, Sweden and Finland, and also the workers compensation statutes in which the claimants' rights to access to courts and jury trial have been laid aside in favour of prompt, equitable and certain compensation.

The details of the Model Medical Accident Compensation Act are then set out in some detail but with reasonable clarity and are followed by expert speculation on the financial consequences of the proposal. The concluding chapter returns to the important question of the constitutionality of the proposals, and the "trade-off" of the constitutional right of the individual to seek redress in the courts, against the greater speed and certainty of the proposed Model Act.

For the reader not well versed in law the text is not easy going but it is by no means insuperable, thanks to the layout of the chapters and their clear division under sub-headings, together with conclusions and, in some cases, a brief introduction from the editors. There are numerous references mainly to American legal literature, and the index is comprehensive.

JOHN EVANS

Ambulatory EEG Monitoring. Edited by JOHN S EBERSOLE. (Pp 383; \$86.50). New York: Raven Press, 1989.

This volume provides a workman-like compendium to every detail of the techniques of 
ambulatory EEG monitoring (or cassette monitoring, as it is often designated now on the basis that most patients are not ambulatory throughout the recordings!). Applications in patients with seizure disorders or with sleep disorders are each addressed by a technological section followed by a series of clinical studies. Most of the 21 chapters are written by North American authors, with contributions from Dr Ebersole's team at Yale, and others from groups at Harvard and Duke Universities, San Diego, Ottawa, Montreal, Dallas, New York, Oxford and Newcastle.

Portable cassette recordings can provide unique insights into clinically relevant alterations in the physiology of patients occurring in their normal home and working environments. New techniques have made a major contribution, especially in the field of epilepsy. Ambulatory EEG recorders began to be used experimentally in the early 1970's and have developed substantially since that time. The advanced technology and analysis methods described for ambulatory EEG monitoring and the precise definition of applications and strategies have materially enhanced the clinical value of such recordings. It is, however, still a highly skilled task to obtain unequivocally reliable information with the limitations of electrodes glued to the scalp connected by several delicate cables to small, portable, battery-operated recorders. Those who use portable music recorders will be well aware of some of the hazards that can arise!

The strengths of the book lie in the immensely detailed, practical information, which occasionally borders on the pedantic or obsessive-but this may account for the success of the techniques in the hands of the authors! It is refreshingly honest to read from some authors that they "had seen that misinterpretation of artefacts as either epileptiform abnormalities or seizures was common" as a preamble to their methods for avoiding such problems. Aminoff's sceptical view of the value of detecting interictal or sub-clinical EEG abnormalities is quoted together with his emphasis that the place of ambulatory monitoring is in documenting events during actual or possible seizures. This opinion is confirmed by careful perusal of the propagation of the ictal discharges illustrated in samples from 8-channel recordings, particularly in the important material from presurgical evaluation. The wide variation in the quality of the illustrated recordings indicates the need for good replay systems and demonstrates the value of automated methods.

The sections on children and neonates are some of the most novel. The neonatal and the EEG/ECG monitoring exemplify the value of a polygraphic approach. This is best seen as one moves on to the somewhat shorter sleep disorder section. Here are given clear accounts of the state of the art with clear definitions of terminology perhaps less familiar to many neuroscientists than those for epilepsy. There is good coverage of the sleep disorders per se as well as of the related respiratory disorders and periodic movements of sleep. All in all this is a worthwhile book which merits a place in neurological and neurophysiological libraries. It will undoubtedly encourage more careful and thoughtful use of the modern ambulatory EEG monitoring techniques and this can only benefit our patients.

PAMELA PRIOR
Atlas of Spinal Surgery. By CHARLES A FAGER. (Pp 247 Illustrated; Price: 662.35 .) London: Lea \& Febiger (UK) Ltd, 1989.

First, let's get one thing straight. This is not an "Atlas of Spinal Surgery". The reader will find nothing about congenital, neoplastic or traumatic conditions of the spine, to mention just three of the areas not covered. What he or she will discover, however, is a most detailed account of one surgeon's experience in the treatment of degenerative diseases of the cervical, dorsal and lumbar spine.

It is an unusual book for this day and age. We are so accustomed to multi-author texts containing myriads of chapters, each focusing down on the contributor's chosen speciality, often with little sense of the editor's original concept and, in the larger volumes, considerable overlap between the chapters. A single author text dealing with such an enormous subject, particularly if written by a busy clinician, is clearly going to suffer from the omission of some essential subjects as, for example, the mechanics of the spine and patho-physiology of disc degeneration. However, a great deal can be gained. Despite the profusion of medical and surgical literature, there remains no substitute for the clear expression of experience and it is in this area that the volume under review scores so highly. In other words, it carries the unmistakable bouquet of having been written by someone who is actually doing the work.

The format is simple. The text has been kept to a minimum and most of the pages are filled either with well chosen radiographs or excellent illustrations by Anne Green (this proportion of illustrations to text presumably accounts for the book being described as "An Atlas").

Many will not agree with the author's surgical recommendations. For example, his operations are nearly always posterior in approach, whether the problem be in the cervical, dorsal or lumbar regions. A resident eager to learn the details of an anterior cervical fusion or a costo-transversectomy will search in vain for any description in these pages. What he or she will find instead will be a most detailed account of how to deal with the spinal degenerative conditions (as they present to the Neurosurgeon) in a way that has been tested countless times by the author refined as circumstances have demanded and shown in his hands to be both safe and effective.

There is also no description of a microdiscectomy. The author has long been associated with opposition to this procedure but this interpretation of his views is simplistic. What he maintains, and it is difficult to disagree with him, is that in order to achieve an effective nerve root decompression in the lumbar region, a great deal more than the removal of a sequestrated disc fragment may be required. A significant amount of bone work may also be needed and he disputes whether all the advocates of micro-discectomy are in fact able to carry out a sufficiently radical procedure through their more limited approach. The proponents of micro-discectomy, on the other hand, maintain that everything that is necessary for an effective operation can indeed be achieved if the instrumentation is used correctly. Only time will tell whose view is correct. At the moment, Dr Fager maintains that it is not how you do it which is important so much as what you do, and from his experience with "failed backs", the micro-discectomists may not always be achieving the goals they set themselves.

Overall, despite the limited procedures it covers (and which I have detailed above) I think this is an excellent book. It is beautifully produced and I would have no hesitation in recommending it to a resident who wished to embark upon a process of selfeducation in a branch of neurosurgery, noted not only for its prevalence but also for the morbidity which may follow its operative management.

RICHARD HAYWARD

Neurology: A Concise Clinical Text. Edited by MICHAEL SWASH AND MARTIN S SCHWARTZ. (Pp 400; £14.95). London: Baillière Tindall, 1989.

The publishers state this book is intended primarily for medical students. It meets this claim admirably. I only wish that, as a medical student, I had seen a book of such width and wisdom.

The section on "symptoms and signs" is a little gem. Students of my generation usually took years to learn - the hard way-what the authors trumpet in their very first chapter, namely that "the pattern of symptoms and signs is the consequence of the interaction between patient and doctor, rather than an absolute and immutable state of affairs". I particularly liked the discussion of pain, with its emphasis on the influence of cultural and educational determinants on subjective experience.

The effect of the observer on the thing observed is a central pre-occupation of modern physics. It is refreshing to see the notion applied to what we do in the consulting room. How many young doctors, even now, have fully grasped that it takes two not only to tango but to elicit most neurological signs? In practice this means that concentric constriction of the visual fields is much more likely to be due to a doctor in a hurry than to hysteria, retinitis pigmentosa or to poisoning with quinine.

Although the book (and its Index) runs to 400 pages it can easily be put in one's pocket. It is "concise" in that it deals with essentials. But it deals with them in a sophisticated and logical way, summarising the main facts in a series of well thought-out tables. The book, as claimed, is essentially "clinical", the student in search of wider pastures being guided, for each chapter, to well chosen references. Emphasising current concerns that students see their patients' problems in a wider perspective the book contains some useful addresses to which the afflicted and their relatives may turn for information and advice. These include the address of the Myalgic Encephalomyelitis Association. The condition is not however acknowledged in the Index - a realistic compromise.

After the plaudits, some protests. Gentamicin is consistently misspelt. Supranuclear palsies fit awkwardly in the section on diplopia. Enophthalmos is still described as if it were, in man, a cardinal-rather than an occasional, even a disputed-feature of an oculosympathetic lesion. Students will be startled to learn (p9) that "prior to Roentgen's discovery of x-rays in 1895 only the first cranial nerve could be visualised, using the ophthalmoscope". Or (p150) that 